\title{
Risk of Malignancy in a Multinodular Goiter: Report of Two Cases with a Literature Review
}

\author{
MY Razaleigh ${ }^{1}$, A Nor Safariny $^{2}$, B Anita ${ }^{3}$
}

\section{Abstract}

Goiter is a common disease in Malaysia. It can be classified as retrosternal, substernal, and intrathoracic goiter. According to this classification, the approach to surgery differs. We have two cases presented with a multinodular goiter with evidence from imaging and histopathology. Both cases were treated as intrathoracic goiters and underwent thyroidectomy with the postoperative pathology report indicating them as micropapillary carcinomas. We will discuss regarding management options for both patients according to the pathology. In conclusion, management will differ based on classification and postoperative pathology reports.

Keywords: Intrathoracic goiter, Micropapillary carcinoma, Multinodular goiter.

World Journal of Endocrine Surgery (2019): 10.5005/jp-journals-10002-1262
\end{abstract}

\section{INTRODUCTION}

Goiter is a common disease in Malaysia. Our hospital has had experience in variable types and sizes of goiters. However, subgroups of a multinodular goiter should be known. There are retrosternal, substernal, and intrathoracic goiters. Many classifications have been given for this, as approach to surgery differs. To treat a benign intrathoracic multinodular goiter with an intraoperative pathology report of micropapillary thyroid carcinoma can be challenging. We will discuss about two cases in keeping with this scenario.

\section{Case Description}

\section{Case 1}

A 42-year-old Malay lady presented with a painless neck swelling for 4 years that is gradually increasing in size. She sought medical treatment owing to obstructive symptoms such as dysphagia to solid food and dyspnea. She had intermittent hyperthyroid symptoms such as palpitation and easily getting agitated. Otherwise, she denied any constitutional symptoms. On examination, there was a diffuse swelling of the left thyroid lobe with a retrosternal extension and the right thyroid lobe was normal. Thyroid function tests and vocal cord assessment were normal. A fineneedle aspiration cytology (FNAC) was carried out and the result showed a colloid goiter. A CT scan of the neck was done, which showed a left thyroid lobe enlargement, causing a partial compression of the trachea (Figs 1 and 2). A left hemithyroidectomy was performed and an isolated left thyroid nodule measuring $12 \mathrm{~cm} \times$ $6 \mathrm{~cm}$ and weighing $122 \mathrm{~g}$ was found (Fig. 3). The specimen was sent for a histopathological examination and the report showed a micropapillary carcinoma with $1 \mathrm{~mm}$ diameter and a nodular hyperplasia.

\section{Case 2}

A 40-year-old Malay lady had a history of anterior neck swelling for more than 10 years. Neck swelling was increasing in size and developed hoarseness of the voice. She has no any obstructive or constitutional symptoms. Her mother had undergone a total
${ }^{1-3}$ Department of Surgery, Hospital Putrajaya, Putrajaya, Malaysia

Corresponding Author: MY Razaleigh, Department of Surgery, Hospital Putrajaya, Putrajaya, Malaysia, Phone: +60 122911204, e-mail: razaleighyusof@yahoo.com

How to cite this article: Razaleigh MY, Safariny AN, et al. Risk of Malignancy in a Multinodular Goiter: Report of Two Cases with a Literature Review. World J Endoc Surg 2019;11(2):60-63.

Source of support: Nil

Conflict of interest: None

thyroidectomy, but she was not sure about the reason. On clinical examination, the right lobe was $4 \mathrm{~cm} \times 3 \mathrm{~cm}$ and the left lobe $4 \mathrm{~cm} \times 5 \mathrm{~cm}$ with no palpable cervical lymph nodes. Her thyroid function tests and vocal cord assessment were normal. A fine needle aspiration cytology (FNAC) was performed and the result was suggestive of nodular colloid goiter with cystic degeneration. Ultrasound of the neck showed features consistent with those of a multinodular goiter. CT of the neck showed a multinodular goiter with no vascular encasement (Fig. 4). Total thyroidectomy

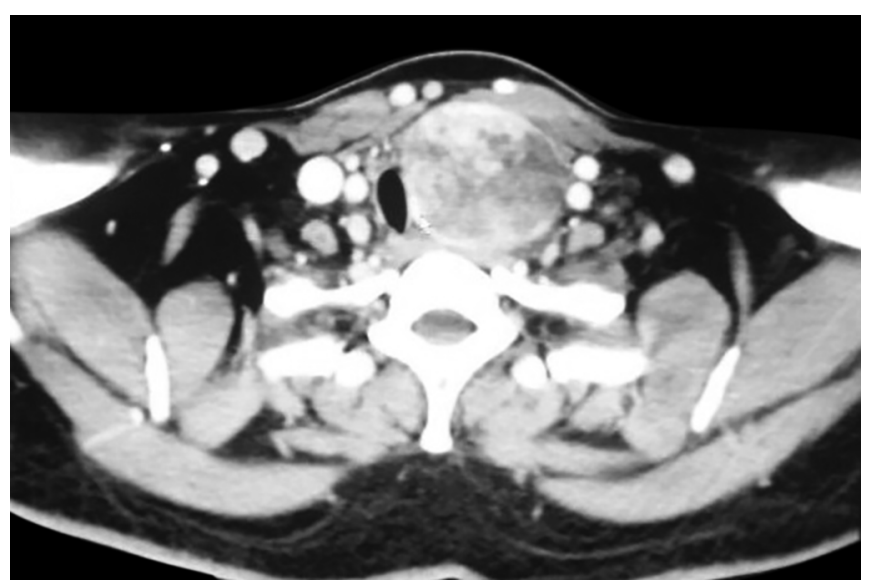

Fig. 1: Axial CT of the neck

(c) The Author(s). 2019 Open Access This article is distributed under the terms of the Creative Commons Attribution 4.0 International License (https://creativecommons. org/licenses/by-nc/4.0/), which permits unrestricted use, distribution, and non-commercial reproduction in any medium, provided you give appropriate credit to the original author(s) and the source, provide a link to the Creative Commons license, and indicate if changes were made. The Creative Commons Public Domain Dedication waiver (http://creativecommons.org/publicdomain/zero/1.0/) applies to the data made available in this article, unless otherwise stated. 


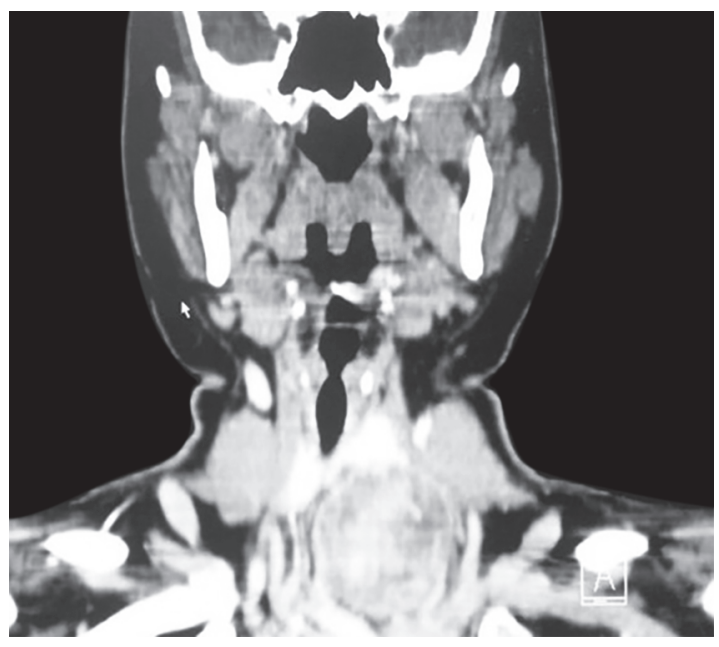

Fig. 2: Sagittal CT of the neck

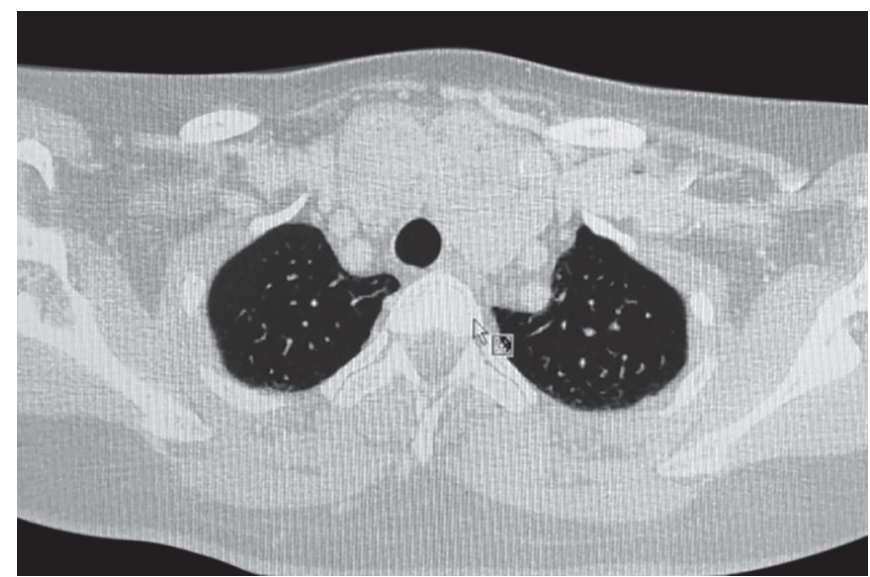

Fig. 4: Axial CT of the neck

revealed a multinodular goiter consisting of a right lobe measuring $5 \mathrm{~cm} \times 6 \mathrm{~cm}$, a left lobe measuring $7 \mathrm{~cm} \times 8 \mathrm{~cm}$, and the total weight of the removed gland was $272 \mathrm{~g}$ (Fig. 5). The whole specimen was sent for a histopathological examination and the report showed a micropapillary carcinoma with $3 \mathrm{~mm}$ diameter and a nodular hyperplasia.

\section{Discussion}

Multinodular goiter refers to an enlarged thyroid gland with multiple nodules. This results from biosynthetic defects, iodine deficiency, autoimmune disease, or nodular diseases. Complications of untreated multinodular goiter can cause clinical symptoms such as dyspnea or dysphagia. Protuberance of goiters is usually easily noticed and are often treated medically or removed surgically. Lin and Chang reported that intrathoracic goiters account for $0.2-45 \%$ of all goiters and most commonly affect women in their sixth and seventh decades of life. The thoracic cavity provides some interior space; therefore, goiters located within can enlarge progressively without symptoms and grow to a considerable size. ${ }^{1}$ Patients with a multinodular goiter require a careful evaluation for the risk of malignancy within the multiple nodules, selecting patients who

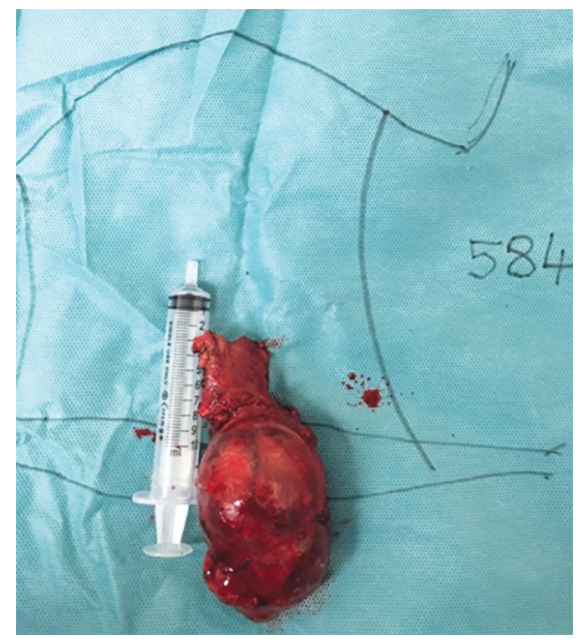

Fig. 3: An intraoperative left hemithyroidectomy specimen

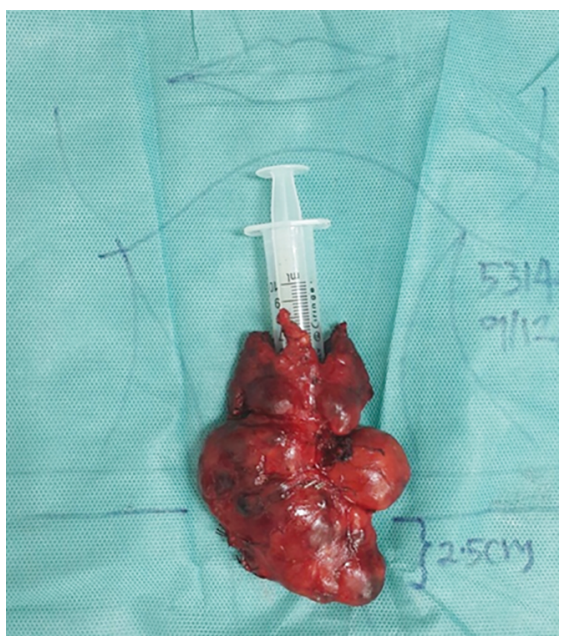

Fig. 5: An intraoperative total thyroidectomy specimen

require surgery, and planning an appropriate surgical approach to address the disease without an undue risk of complications. Morphological and molecular studies suggest a degree of polyclonal etiology. Multinodular goiters are sometimes familial and one study suggests linkage to a DNA mother as chromosome $14 \mathrm{q} .{ }^{2}$

Haller first provided an anatomical description of the intrathoracic goiter in 1794, since then a number of names and descriptions such as retrosternal, substernal, retroclavicular, and intrathoracic goiter has been given. Intrathoracic goiter can be classified as "incomplete" or "complete". The goiter is "incomplete" when a major portion in the neck is visible, with its lower pole being substernal, subclavicular, or intrathoracic. Conversely, "complete" or true is completely in the mediastinum. Thus, the uppermost part is barely palpable in the sternal notch. ${ }^{3}$ There is also primary, which are ectopic thyroid tissue detached from a cervical thyroid mass and is very rare $(1 \%)$, or secondary, which is more common where a portion of the goiter extends retrosternal.

Although goiters are mostly thought to be benign, but this type of goiter has a risk for malignancy. For a thyroid gland to reach a sufficient size to pass into the mediastinum, the pathological processes involved must have been present for many years. It is therefore unsurprising that the vast majority of surgical specimens 
demonstrate a benign pathology. The rate of malignancy in reported surgical series, however, is low (6-21\%). However, it is important to consider malignancy because it may significantly alter management. ${ }^{4}$

Micropapillary thyroid carcinoma is defined as a papillary carcinoma of the thyroid that is less than $10 \mathrm{~mm}$ in diameter. Merdad et al. ${ }^{5}$ summarized the latest thyroid nodule management guidelines published by the European Thyroid Association (ETA; 2006), British Thyroid Association (BTA; 2007), and American Thyroid Association (ATA; 2009). The management of micropapillary thyroid carcinoma are as shown in Table 1.

Simo et al. described a surgical approach for intrathoracic goiters. It poses significant intra and postoperative challenges. There are differences between total and hemithyroidectomy approach. Total thyroidectomy is indicated for bilateral thyroid gland enlargement. However, in patients with unilateral enlargement or posing a significant risk to the recurrent laryngeal nerve or parathyroid function, thyroid lobectomy is a perfectively acceptable option as the majority of goiters will be benign. ${ }^{4}$

The option of cervical and extracervical approach should be considered. Most commonly cervical approach is suitable for $95 \%$ of intrathoracic goiters. The extracervical approach would require sternotomy and moreover when an intrathoracic goiter is significantly located in the mediastinum, retrotracheal, or retroesophageal position, or if the intrathoracic component is significantly larger than the cervical one. The main indications for an extracervical approach therefore are a giant intrathoracic extension, recurrent goiters, presence of malignancy with an extrathyroidal extension, an extension posterior to trachea and esophagus, an extension between trachea and esophagus, Isolated mediastinal goiters, and intrathoracic goiters with a diameter greater than the diameter of the thoracic inlet. ${ }^{1,2}$

According to British Thyroid Association for Management of Thyroid Cancer, ${ }^{6}$ surgery for micropapillary thyroid carcinoma with less than $10 \mathrm{~mm}$ in diameter can be treated adequately by thyroid lobectomy provided that:

- The tumour does not extend beyond the thyroid capsule

- There is no evidence of metastases

- There is no evidence of vascular invasion

- There is no evidence of multifocality

- There is no evidence of contralateral disease.

A subsequent treatment to consider for managing a micropapillary thyroid carcinoma is radio active iodine (RAl) and follow-up. As summarized by Merdad et al., RAI is not required if a complete surgery is done with a unifocal or multifocal margin of $<1$ $\mathrm{cm}$ without an extrathyroidal extension with the staging of NOMO. From this, whether a decision for RAl is required is clear. There is no guideline regarding the years to do follow-up of patients with a micropapillary thyroid carcinoma; however, multiple studies have been conducted to detect the recurrence rate but it varies in duration.

Noguchi et al. stated that the diagnosis of a benign nodule shows a slightly better prognosis than a preoperative diagnosis of a malignant nodule and also a tumour size of $1-5 \mathrm{~mm}$ gives an improved recurrence-free survival rate when compared to a size of 6-10 $\mathrm{mm}^{7}$

Table 1: Summary of ATA, BTA, and ETA management recommendations (Merdad et al.) ${ }^{5}$

\begin{tabular}{|c|c|c|c|}
\hline ATA & & BTA & ETA \\
\hline \multirow[t]{4}{*}{ Investigate } & $>5 \mathrm{~mm}$ if: & $\begin{array}{l}\text { Can be managed by a primary care } \\
\text { physician if: }\end{array}$ & FNAC only if: \\
\hline & $\begin{array}{l}\text { Suspicious US findings (microcalcifications; } \\
\text { hypoechoic; increased nodular vascularity; } \\
\text { infiltrative margins; taller than wide on } \\
\text { transverse view). }\end{array}$ & Non-palpable & $\begin{array}{l}\text { Suspicious finding on US (solid } \\
\text { hypoechoic with microcalcifications) }\end{array}$ \\
\hline & $\begin{array}{l}\text { A history of head and neck radiation, or } \\
\text { history of thyroid cancer in one or more } \\
\text { first-degree relatives, }\end{array}$ & Incidentally found & Personal history \\
\hline & Abnormal cervical lymph nodes & No concerning features & \\
\hline \multirow[t]{8}{*}{ Surgery } & Lobectomy sufficient if: & Lobectomy sufficient if: & Lobectomy sufficient if: \\
\hline & No associated lymphadenopathy & $\begin{array}{l}\text { Lymph node negative and } \\
\text { followed by levothyroxine therapy }\end{array}$ & $\begin{array}{l}\text { No evidence or nodal or distant } \\
\text { metastasis }\end{array}$ \\
\hline & $\begin{array}{l}\text { No history of head and neck radiation or a } \\
\text { positive family history of thyroid cancer }\end{array}$ & No multifocality & $\begin{array}{l}\text { No history of previous radiation } \\
\text { exposure }\end{array}$ \\
\hline & Low risk, unifocal, and intrathyroidal & No extrathyroidal spread & Multifocality \\
\hline & nodule & No family disease & Extrathyroidal extension \\
\hline & & No metastasis & Vascular invasion \\
\hline & & No vascular invasion & Unfavorable histology \\
\hline & & No contralateral disease & \\
\hline \multirow[t]{6}{*}{ RAI } & $\begin{array}{l}\text { Recommended if: distant metastasis or gross } \\
\text { extrathyroidal extension }\end{array}$ & Omit if: & No indication if: \\
\hline & Not recommended if: & Unifocal & Complete surgery \\
\hline & Unifocal and no high risk features & NOMO & Favorable histology \\
\hline & Multifocal with all nodules $<1 \mathrm{~cm}$ & No extension beyond the thyroid & NOMO \\
\hline & Selective use if regional lymph node metas- & Favorable histology & No extrathyroidal extension \\
\hline & tasis & Complete surgery & \\
\hline
\end{tabular}




\section{Conclusion}

Both of our cases were incomplete intrathoracic multinodular goiters that apparently looked to be benign. A thyroidectomy was performed using the cervical approach and did not require a sternotomy. Despite a low risk of malignancy in such types of goiters, the possibility of a micropapillary carcinoma should be ruled out. In our cases, although the cytological examinations of the aspirated glands were negative for malignancy, intraoperative thyroid samples showed micropapillary carcinomas. In both patients, having complete surgery, no extrathyroidal extension, and a tumor diameter of $<5 \mathrm{~mm}$ no RAl was required. Both of them did not require any further postoperative treatment and was reviewed in the clinic. Both patients are well during the follow-up and showed no evidence of recurrence.

\section{References}

1. Lin YS, Chang HC. Giant intrathoracic goitre: a case report. OA Case Rep 2013 May 01;2(4):39.

2. Cohen JP. Substernal Goiters and Sternotomy. Laryngoscope 2009 Apr;119(4):683-688. DOI: 10.1002/lary.20102.

3. Asciak PP, Higgins K. Management of intrathoracic Goitre. Can J Surg 2008 Oct;51(5):E111-E112.

4. Simo R, Nixon I, et al. Surgery For Intrathoracic (Retrosternal) Goitres. Open Access Atlas Otolaryngol Head Neck Oper Surg; 1-17.

5. Merdad M, Eskander A, et al. Current Management of Papillary Thyroid Microcarcinoma in Canada. J Otolaryngol Head Neck Surg 2014;43:32.

6. Association BT. Guidelines for the Management of Thyroid Cancer (2nd Edition). In: Physicians RCo. 2nd ed., Great Britain: The Lavenham Press, Suffolk; 2007.

7. Noguchi S, Yamashita H, et al. Papillary Microcarcinoma. World J Surg 2008 May;32(5):747-753. DOI: 10.1007/s00268-007-9453-0. 